\title{
Implications of climate change mitigation strategies on international bioenergy trade
}

\author{
Vassilis Daioglou, et al. [full author details at the end of the article]
}

Received: 24 December 2017 / Accepted: 24 September 2020/Published online: 11 October 2020

(C) The Author(s) 2020

\begin{abstract}
Most climate change mitigation scenarios rely on increased use of bioenergy to decarbonize the energy system. Here we use results from the 33rd Energy Modeling Forum study (EMF-33) to investigate projected international bioenergy trade for different integrated assessment models across several climate change mitigation scenarios. Results show that in scenarios with no climate policy, international bioenergy trade is likely to increase over time, and becomes even more important when climate targets are set. More stringent climate targets, however, do not necessarily imply greater bioenergy trade compared to weaker targets, as final energy demand may be reduced. However, the scaling up of bioenergy trade happens sooner and at a faster rate with increasing climate target stringency. Across models, for a scenario likely to achieve a $2{ }^{\circ} \mathrm{C}$ target, $10-45 \mathrm{EJ} /$ year out of a total global bioenergy consumption of 72-214 EJ/year are expected to be traded across nine world regions by 2050 . While this projection is greater than the present trade volumes of coal or natural gas, it remains below the present trade of crude oil. This growth in bioenergy trade largely replaces the trade in fossil fuels (especially oil) which is projected to decrease significantly over the twenty-first century. As climate change mitigation scenarios often show diversified energy systems, in which numerous world regions can act as bioenergy suppliers, the projections do not necessarily lead to energy security concerns. Nonetheless, rapid growth in the trade of bioenergy is projected in strict climate mitigation scenarios, raising questions about infrastructure, logistics, financing options, and global standards for bioenergy production and trade.
\end{abstract}

Keywords Bioenergy trade $\cdot$ Climate policy $\cdot$ Energy security $\cdot$ Scenario analysis $\cdot$ Integrated assessment models $\cdot$ EMF

\footnotetext{
This article is part of the Special Issue on "Assessing Large-scale Global Bioenergy Deployment for Managing Climate Change (EMF-33)" edited by Steven Rose, John Weyant, Nico Bauer, Shinichiro Fuminori, Petr Havlik, Alexander Popp, Detlef van Vuuren, and Marshall Wise.

Matteo Muratori performed his work while at Pacific Northwest National Laboratory and Patrick Lamers performed his work while at Idaho National Laboratory (INL), Idaho Falls, Idaho, USA
}

Electronic supplementary material The online version of this article (https://doi.org/10.1007/s10584-02002877-1) contains supplementary material, which is available to authorized users. 


\section{Introduction}

Climate change mitigation scenarios, as projected by several integrated assessment models (IAMs), show that bioenergy may play a crucial role in meeting strict climate targets (Clarke et al. 2014; Rose et al. 2014; Bauer et al. 2018; Muratori et al. 2020). Biomass is a particularly attractive energy source due to its ability to be converted into a number of secondary and final energy carriers (solid fuels, liquid fuels, heat, electricity, and hydrogen), its supply consistency (vs. intermittency issues of other renewable energy sources) and its ability to result in carbon dioxide removal (when used in combination with carbon capture and storage, CCS). In IAM scenarios, primary bioenergy (i.e., biomass feedstock) may be produced far from conversion and consumption points and thus international trade of potentially large volumes of bioenergy is implicit in mitigation strategies. Moreover, earlier IAM work shows little agreement concerning the projected major primary bioenergy supply regions (Chum et al. 2011; Searle and Malins 2015; Creutzig et al. 2015; Rose et al. this issue).

Total global bioenergy trade volumes exceeded $1 \mathrm{EJ} /$ year in 2015 , of which $60 \%$ was directly traded for energy purposes (e.g., biodiesel, wood pellets) and $40 \%$ for other purposes where part of the primary bioenergy was used for energy during the final processing (e.g., black liquor and sawdust combustion from imported roundwood) (Proskurina et al. 2017b). Global solid bioenergy trade mainly originates from countries with a strong forestry sector including Canada, the USA, Russia, and Southeast Asian countries such as Vietnam. Whereas local trade of wood chips, fuel wood, and waste wood (especially within the EU) is significant (Lamers et al. 2012; Dadhich 2017), intercontinental trade of solid bioenergy is almost all wood pellets. The dominant trading patterns in 2018 include flows from the USA and Canada to the EU, with new trade routes emerging towards South Korea and Japan. The main supply regions for liquid biofuels as well as their feedstocks (e.g., vegetable oils) have been low-cost agricultural production centers including Argentina (mainly soy oil biodiesel), Brazil (mainly sugarcane-derived ethanol), the USA (mainly corn-derived ethanol), and Malaysia and Indonesia (mainly palm oil biodiesel). The trade in (first generation) liquid biofuels (ethanol, biodiesel, and vegetable oil) varies from year to year in terms of volumes and trade routes, primarily due to changing subsidy regimes, anti-dumping measures, etc. Trade of advanced (second generation) liquid biofuels is currently negligible.

Given that most countries are members of the World Trade Organization (WTO) and thus agree to abide by its rules, tariffs have played a less prominent role in shaping long-term trade routes with the exception of short-term triangular trade to circumvent specific tariffs or measures. Examples include EU biodiesel imports from Argentina via the USA or US imports of Brazilian ethanol via the Caribbean Basin Initiative member states. Historically, triangular trade has accounted for between one quarter and three quarters of trade shares for periods of up to 3-5 years, i.e., until new regulations were enforced (Lamers et al. 2011, 2014a). Trade restrictions and requirements, such as phytosanitary measures to avoid the accidental import of pests through untreated wood chips, and legislation with respect to sustainability constraints, have been much more important in limiting the volume and routes of international bioenergy trade (Junginger et al. 2011). Past bioenergy trade has been stimulated by incentives that promote the use of bioenergy as part of a renewable energy or climate strategy. For example, in the EU, quota systems for renewable energy, taxation of fossil fuels, the emission trading scheme, and government support have influenced bioenergy demand and consequently its trade (Lamers et al. 2012). Thus, policies aimed at meeting strict climate targets such as those of the Paris agreement are likely to further stimulate bioenergy trade. 
Though a number of studies have analyzed past and present international bioenergy trade (Lamers et al. 2011; Lamers et al. 2012; Junginger et al. 2011; Proskurina et al. 2017a), or energy security in general (Cherp et al. 2016; Jewell et al. 2016), to date, there are very few studies concerning the future role of international bioenergy trade (Matzenberger et al. 2015; Hansson and Berndes 2009). Among the existing studies there has been no systematic analysis of long-term international trade in climate change mitigation scenarios. Thus, while previous assessments have highlighted the potential importance of bioenergy trade, they offer few insights due to the limited and inconsistent nature of the results. These include the lack of consistent scenario storylines (i.e., the drivers of energy demand such as population growth, climate policy, bioenergy technology availability), a focus on specific regions lacking insight on the global context, use of partial models focusing either on supply or demand, and limited comparison of results across different models and modeling techniques. This raises important questions concerning the future international bioenergy trade. These include how it is expected to grow given the use of bioenergy as a climate change mitigation measure, how the reliance on bioenergy trade may affect regional energy security, and what are the implications of international bioenergy trade on global climate policies. Understanding the potential role of international bioenergy trade in mitigation scenarios allows for an improved evaluation of the availability and the role of bioenergy in reducing emissions, and the trade-off between emission mitigation in net importing regions and land-use change emissions in net exporting regions.

This study builds upon the results of the EMF-33 (33rd project of the Energy Modeling Forum) multi-model comparison project where IAMs projected bioenergy supply and demand across a set of harmonized scenarios. The scenarios include several different climate change mitigation targets and sensitivities concerning bioenergy technology availability (Bauer et al. 2018). By leveraging the EMF-33 results, this analysis goes beyond previous assessments of long-term international bioenergy trade in a number of aspects. In this paper, we first compare how different IAMs represent international trade of bioenergy. Subsequently, we present their projections of bioenergy trade across different scenarios in order to better understand the role of international bioenergy trade in future energy systems. Specifically, we focus on the importance of this trade in climate change mitigation scenarios. This is the first study that systematically compares bioenergy trade modeling and results for a broad range of models and scenarios. It analyzes the differences in model results and modeling assumptions at the interface of primary bioenergy feedstock production and final bioenergy use as it investigates trade that balances regional demand and supply. Furthermore, we discuss what future challenges may arise in realizing these projections.

In section 2, we outline the definitions and the scope of this study, while in section 3 a brief overview of how each model represents international bioenergy trade is reported. Section 4 presents the projections of volumes of bioenergy trade, the implied financial flows, the drivers of bioenergy trade, and implications for energy security. Section 5 provides a discussion on how these compare to past and present bioenergy trade and what practical challenges must be resolved in order to realize the projections. Finally, in section 6, we summarize our findings.

\section{Method}

\subsection{Model and scenario selection}

This paper analyzes the results of eight IAMs across seven scenarios (Table 1). The model and scenario selections are based on the EMF-33 study which compares a broad suite of global 
Table 1 Scenarios used in this study

\begin{tabular}{ll}
\hline Scenario & Assumptions \\
\hline Baseline & $\begin{array}{r}\text { No additional climate policy, all advanced technologies available according } \\
\text { to model settings } \\
2011-2100 \text { energy related } \mathrm{CO}_{2} \text { budget limited to 1600Gt, unlikely to meet the } \\
\text { Budget1600 }\end{array}$ \\
& $2{ }^{\circ} \mathrm{C}$ target, all advanced technologies available according to model settings \\
Budget1600-NoBECCS & Same as Budget1600, but bioenergy with CCS technologies are not available \\
Budget1600-NoFuel & Same as Budget1600, but advanced (lignocellulosic) biofuels are not available \\
Budget1600-None & Same as Budget1600 but no advanced bio-technologies are available \\
Budget1000 & $2011-2100$ energy-related $\mathrm{CO}_{2}$ budget limited to 1000Gt, limiting global average \\
& warming to $2{ }^{\circ} \mathrm{C}$, all advanced technologies available according to model settings \\
Budget400 & $2011-2100$ energy-related $\mathrm{CO}_{2}$ budget limited to 400GtC, aiming towards to \\
& $1.5{ }^{\circ} \mathrm{C}$ target, all advanced technologies available according to model settings \\
\hline
\end{tabular}

multi-region IAMs, with the aim of performing a detailed analysis of the availability of bioenergy technologies and their role in achieving a set of emissions budgets. The models included in EMF-33 endogenously project the development of the energy and land systems. All models include some form of advanced bioenergy technologies such as lignocellulosic biofuels, and bioenergy with carbon capture and storage (BECCS). An overview of the bioenergy demand projections across different climate mitigation targets and bioenergy technology portfolios is available in Bauer et al. (2018), while Daioglou et al. (2020) presents and assesses the techno-economic and energy system assumptions across the model suite. The study of supply-side potentials by Rose et al. (this issue) focuses on the primary bioenergy supply across scenarios of harmonized demand. With its focus on bioenergy trade, this paper connects the use of bioenergy and its production across regions.

All models participating in the EMF-33 study have some common structural elements. First, each IAM endogenously models the flexibility of both the energy and land systems, and their response to greenhouse gas emission budgets. Thus, both the supply and demand of bioenergy, and the interaction between the land-use and energy systems are represented in each model. Additionally, the models provided results at an adequate level of regional (dis)aggregation (see section 2.2). Finally, only models that reported results for international trade of primary or secondary bioenergy are included in this paper. Overall, from the 12 models participating in the EMF-33 exercise, eight are included in this study.

This study considers a set of scenarios differentiated by their climate change mitigation targets (different carbon budgets) and availability of different bioenergy technologies. The scenarios considered in this paper are outlined in Table 1. The scenarios were chosen to assess the importance of bioenergy trade in meeting different climate change mitigation goals and how this trade may vary across their climate goal stringency. Along with a Baseline scenario with no climate policy, mitigation goals include carbon budgets for the energy system motivated by the goals of the Paris Agreement (Rogelj et al. 2015). The carbon budgets are harmonized for the energy system only to remove variability across models concerning landbased emissions and mitigation. This allows for comparison of the use of bioenergy in the energy system across models in different climate change mitigation scenarios. This, however, means that land-use emissions, which may vary across models, are not part of the emission budget (Bauer et al. 2018). Yet, for each model, all GHG emissions (including land-use emissions) are consistently priced on a $\mathrm{CO}_{2}$ equivalent basis. Thus, while direct and indirect land-use change emissions, as well as land-based mitigation measures (i.e., afforestation) are 
not part of the budget, they are accounted for and priced in the mitigation scenarios. To better highlight the drivers of international bioenergy trade besides the requirement for low-carbon energy carriers, we also include scenario variations on bioenergy technology assumptions. These are done only with the Budget1600 scenario since very few models could solve for stricter budgets and constrained technologies.

\subsection{Regional aggregation}

When dealing with international trade of commodities, regional representation is extremely important. Ideally, all results would be reported at the country level. However, since IAMs tend to aggregate countries into larger regions to reduce data and computational requirements, we inevitably present results across aggregated global regions and key countries (henceforth referred to as "regions"). Thus, the results do not reflect total international trade, but rather the net-trade between specific macro regions. Total international trade (i.e., country-to-country) would be significantly higher. Global numbers, when reported, indicate the sum of the trade between these regions (i.e., the sum of total exports or imports), and thus represent gross trade. The regions considered in this analysis are the EU, USA, Rest of OECD, East Asia ${ }^{1}$, rest of Asia, Brazil ${ }^{2}$, rest of Latin America, Former USSR, and Middle East and Africa.

\subsection{Indicators}

There is an inherent difficulty when it comes to comparing model projections since some models trade primary bioenergy, while others (also) trade secondary biofuels (solid or liquid). In this paper, we present all trade volumes in terms of primary energy. Thus, if a model trades secondary bioenergy (e.g., maize ethanol), the traded volumes are presented in terms of the equivalent primary energy (e.g., maize), calculated based on model and region-specific conversion efficiencies. All volumes are presented on an energy basis (EJ), while financial flows are presented in terms of billion US\$2005. As this study focuses only on the trade of bioenergy commodities, it does not include the trade of agricultural products for food and feed purposes, or the effect of bioenergy production on food security, which is presented in Hasegawa et al. (2020).

This manuscript also intends to elaborate the role and implications of international bioenergy trade on regional energy security. Jewell et al. (2014) define energy security as "low vulnerability of vital energy systems", whose "failure may disrupt the functioning and stability of a society". Accordingly, if in each region bioenergy forms a large portion of its total primary energy supply (TPES), and most of it is imported, it has increased exposure to risk and may suffer from relative energy insecurity. On the other hand, if either bioenergy makes up a relatively small fraction of TPES or it is primarily produced locally, the region has low exposure to risk (concerning bioenergy use). To represent this, we plot the regional bioenergy share in TPES against the fraction of that bioenergy, which is traded. We compare this to the equivalent for fossil fuels in 2010 to highlight how future use of bioenergy compares with current dependence on fossil fuels. Furthermore, we also determine a diversity of supply index

\footnotetext{
${ }^{1}$ This includes China and Japan only. IMACLIM-NLU and REMIND-MAgPIE do not disaggregate Japan; thus, in these models only China is included in "East Asia," while Japan is part of "Rest of OECD."

${ }^{2}$ REMIND-MAgPIE does not disaggregate Brazil specifically; thus, all Latin America is in the "Rest of Latin America" region.
} 
to highlight the possible emergence of supply bottlenecks across scenarios. The above indicators reflect the "sovereignty" perspective of security. They do not, however, address overall resilience which includes the ability to respond. Additionally, the security of supply may be disrupted by droughts, crop failures, and other causes (Cherp and Jewell 2011) and the assessment of these risks is beyond the scope of this analysis.

\section{Representation of bioenergy trade in IAMs}

All the IAMs used in this study include representations of both the energy and land systems, and make projections on global and long term (2100) scales. A table summarizing how bioenergy trade is represented in the models participating in this study is available in the Supplementary Material. Overall, different models represent trade differently, for instance, they may trade in either primary or secondary bioenergy, or both. Furthermore, models differ regarding the coverage of bioenergy carriers (1st generation or advanced biofuels), their aggregation of feedstocks and energy carriers (i.e., specific crops versus a single "aggregate" feedstock), and the energy conversion routes.

Most models assume international trade at a single world market price, with COFFEE and IMAGE being the only ones that model bilateral trade between regions. Furthermore, while all models include trade costs in some form, each model represents these costs differently. These are usually based on a basic "trade cost" ignoring specific costs (such as taxes and tariffs, the impact of transport mode and distance, and other specific costs), with IMACLIM-NLU and IMAGE being exceptions as they include tariffs and a "transaction cost," respectively. AIM, COFFEE, and IMACLIM-NLU also directly link trade costs to fuel prices, and thus climate policy may affect trade costs. The models rely on similar assumptions concerning the dynamics that govern international trade. All models assume traded bioenergy is completely homogenous and substitutable across regions, and trade decisions are always based on relative costs (i.e., if imports are cheaper than local production, or if exports are more profitable than local consumption). Furthermore, most of the models ignore specific trade barriers, strict self-sufficiency constraints, or limits on export/import expansion. REMIND-MAgPIE is an exception where a limit is put on the growth of additional trade flows by including adjustment costs (thus increasing trade costs) that depend on trade volumes.

\section{Results}

\subsection{Projections of bioenergy trade}

Figure 1 shows regional net trade of bioenergy across models for the Baseline, Budget1000, and Budget400 scenarios. Regional bioenergy production and trade across all models, and Baseline and Budget scenarios, are presented in Fig. S.1 of the Supplementary Material. Numerical results for all scenarios are available in the Supplementary Data. Overall, though most models show increasing bioenergy trade throughout the century in all scenarios, there is significant disagreement on the volumes traded and net importing/exporting regions. These differences arise from the fact that models determine bioenergy supply and demand differently, leading to significant variation concerning the main supply regions and feedstocks (Rose et al. 


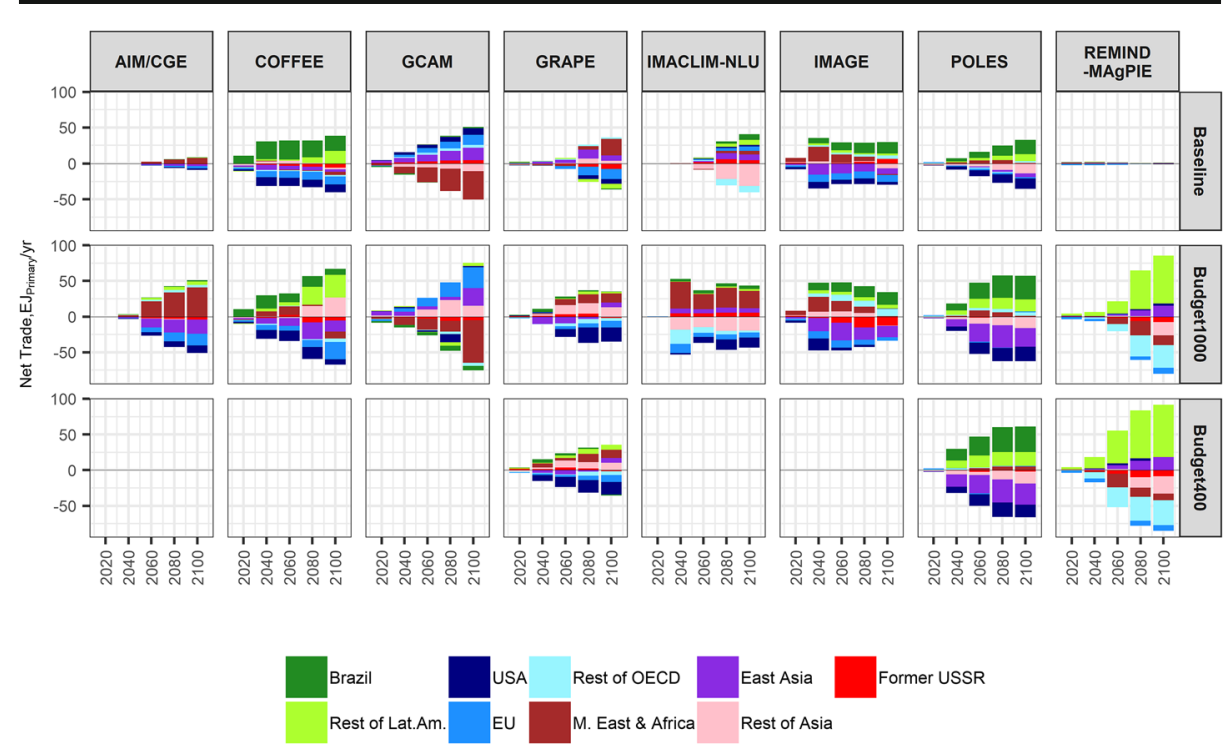

Fig. 1 Net trade of primary bioenergy, in EJ/year, as projected by EMF-33 participating models. Positive values indicate net exports. Note: for REMIND-MAgPIE the "Rest of Latin America" region includes Brazil. Only three models were able to solve the Budget 400 scenarios

this issue). Critical issues in this respect include how models represent land-use allocation, constraints on agricultural expansion, the representation of agricultural and forestry residues, the competition between bioenergy, food, and forestry production, and the projections of relative crop/bioenergy yields between regions. REMIND-MAgPIE is the only model to show almost no trade in the Baseline. This is because REMIND-MAgPIE only trades primary bioenergy and includes additional costs associated with increasing trade. This leads to a situation where it is not worthwhile to trade bulk primary bioenergy unless necessary. Instead, regions consuming bioenergy depend on their local supply, while regions without their own supply find it cheaper to import (or produce) fossil fuels.

The range of global trade volumes across models in 2030, 2050, and 2100 respectively are 0-27, 1-36, and 1-51 EJ/year for the Baseline. For the Budget1600 scenario (not shown in Fig. 1), these are 0-27, 4-44, and 37-72 EJ/year. For the Budget1000 scenario, the ranges are $0-36,10-45$, and 34-86. Finally, the Budget400 scenario trade volumes for 2030, 2050, and 2100 are 12-15, 19-43, and 35-92 EJ/year. This implies that, in each scenario from 2050 onwards up to $50 \%$ of bioenergy consumed globally is traded among the regions defined here (see section 4.3). Most models agree that climate policy increases the volume of traded bioenergy with respect to the Baseline. Increasing the stringency of the carbon budget also increases bioenergy trade but to a lesser extent. This is because stricter climate targets do not necessarily imply greater bioenergy demand as the increased mitigation requirement may be primarily met through reduced energy demand, greater electrification, or deployment of other low carbon energy sources (Bauer et al. 2018).

The annual growth rates of traded bioenergy vary across models and carbon budget scenarios. For the 2020-2050 period, these are 0.1-16.5, 2.9-18, and 5.5-10.4\% per annum for the Budget1600, Budget1000, and Budget400 scenario respectively across models. For the 2020-2100 period, these are 2-7, 1.8-6.8, and 2.9-4.2\% per annum, respectively. For the 
Baseline, these numbers are 0-9 and 0-7\% per annum for the 2020-2050 and 2020-2100 periods respectively. These figures imply that there is faster growth in the first half of the century with growth rates comparable to those previously observed for crude oil (Stopford 2009). Similarly, the main effect of stricter carbon budgets on international trade is timing, with ambitious climate targets projecting a more rapid scaling-up of international bioenergy trade. The REMIND-MAgPIE and GRAPE models are an exception, with growth of bioenergy trade in the latter part of the century. The mitigation scenarios of GRAPE depend on fuel switching to natural gas early on while REMIND-MAgPIE scales up the use of renewable energy sources (solar in particular) early on. Accordingly, both models rely on bioenergy (mostly combined with CCS) only in the second part of the century.

IMAGE and POLES also report net trade in terms of financial flows. As these flows depend on both the volume and the price of bioenergy, the trends follow those of Fig. 1. Both models project increasing revenue for Brazil from bioenergy exports, reaching \$2072 billion/year by 2030, increasing to $\$ 107-241$ billion/year by 2050 for the Budget 1000 scenario. For comparison, in 2011, agricultural exports of Brazil amounted to $\$ 81$ billion (MAPA 2012). On the other hand, according to these models, East Asia is projected to increase its net bioenergy imports from current levels to up to $\$ 226-265$ billion by 2050 in the Budget1000 scenario. Currently, China imports approximately $\$ 200$ billion worth of agricultural products (Gale et al. 2015). This highlights the huge role international bioenergy trade may play in the future concerning trade balances of regions and potential economic growth.

It is important to note that while the results presented highlight trade in terms of equivalent primary bioenergy, specific models may not explicitly trade primary bioenergy (see Table 1 of the Supplementary Material). All models except for IMAGE and POLES trade some sort of primary bioenergy carrier (which is converted at the region of consumption), with REMINDMAgPIE and GCAM solely trading primary bioenergy. From the models that trade both primary and secondary bioenergy, GRAPE and COFFEE primarily trade liquids with primary bioenergy accounting for less than $20 \%$ of total bioenergy trade, while AIM and IMACLIMNLU show opposite behavior. Concerning the models that trade secondary bioenergy only (solids and liquids), POLES projects the trade of solids only, while IMAGE has a more balanced projection, trading both solids and liquids, with the share of solids growing towards the end of the century as bioelectricity with BECCS becomes an increasingly important mitigation measure (Bauer et al. 2018).

The projected trade volumes are generally lower than the current trade of crude oil across these regions ( $90 \mathrm{EJ}_{\text {Prim }} /$ year), but much larger than coal. Increased trade in bioenergy does not necessarily mean that the total trade of energy commodities increases, since mitigation scenarios imply reduced use of fossil fuels. Instead, the increase in trade of bioenergy comes at the expense of fossil fuel trade whose demand, particularly oil, declines in mitigation scenarios. For the Budget1000 scenario, the median — across models - volume of oil traded falls from approximately $90 \mathrm{EJ}_{\text {Prim }} /$ year currently to 67 and $21 \mathrm{EJ}_{\text {Prim}} /$ year by 2050 and 2100 respectively. Over the same period, the median trade of bioenergy increases from less than 1 currently to 25 and $54 \mathrm{EJ}_{\text {Prim }} /$ year, largely mirroring the decline in oil. In the mitigation scenarios, the trade of fossil fuels is increasingly dominated by natural gas and coal (which for some models is combined with CCS to produce low carbon electricity). Overall, all models except for AIM, COFFEE, and GRAPE, project a decline in gross global fossil fuel trade after 2050 in the budget scenarios. Model-specific projections for the trade of fossil fuels and bioenergy are shown in Fig. S.2 of the Supplementary Material. 


\subsection{Regional importance and drivers of bioenergy trade}

Projected use of bioenergy in climate mitigation scenarios depends on bioenergy technology availability, climate change mitigation efforts, and assumptions on technological change (Bauer et al. 2018; Daioglou et al. 2020). As shown in Fig. 1, models show significant variation concerning net importers and exporters.

Figure 2 shows which regions are projected to be net importers (green) or net exporters (pink) for the Budget1000 scenario. By mid-century, most models project that Brazil, the rest of Latin America, and the Middle East and Africa are net exporters of bioenergy. GCAM shows different trends since it projects Brazil to be a major food exporter instead (Muratori et al. 2016). Most models indicate the USA, EU, East Asia, and the former USSR to be net bioenergy importers, with East Asia dominating global imports. These results contrast with recent observations for the USA and the Former USSR which have shown these regions to be net exporters, especially for wood pellets, biodiesel, and fuel ethanol (Lamers et al. 2014a; b; Proskurina et al. 2017a). These regions' domestic demand is projected to increase significantly, especially under stringent mitigation scenarios, reducing their export potential. Furthermore, efficiency improvements, higher potential crop yields, higher land availability, and lower costs make other regions more competitive exporters in the IAM projections. This is particularly true for tropical regions such as Latin America and Africa where supply is projected to outstrip demand.

Figure S.3 of the Supplementary Material shows regional dependence on bioenergy trade. For net exporters, this is the fraction of production destined for export, and for net importers, it is regional consumption supplied from imports. As shown, it is projected that up to $90 \%$ of Brazil's production may be destined for export, and up to 50\% for the rest of Latin America. Conversely, for the USA, EU, Former USSR, and much of Asia, many models project that more than 50\% of their bioenergy demand may depend on imports. The importance of these results concerning the relative importance of bioenergy in consuming regions is discussed in section 4.3. For the rest of the regions, there is little agreement either concerning their role in bioenergy trade, or how important it is to them.

Cumulative (2010-2100) gross global trade across all scenarios and models is shown in Fig. S.4 of the Supplementary Material. By showing cumulative gross global trade, the impact of $\mathrm{CO}_{2}$ budget and technology availability assumptions on global trade can be seen. It is worth noting that models react differently to scenarios that assume different bioenergy technology portfolios. While COFFEE and IMACLIM-NLU show a large drop in their trade of bioenergy when advanced bioenergy technologies are lacking (BECCS and advanced fuels, respectively), other models show a more muted response. Interestingly, GRAPE and REMIND-MAgPIE show an increase in global bioenergy trade in the absence of BECCS. For GRAPE, this is because it deploys more bioenergy in order to decarbonize the energy systems, outweighing the loss of bioenergy use due to the lack of BECCS technologies (Bauer et al. 2018). For REMIND-MAgPIE, while the lack of BECCS reduces the overall use of bioenergy, trade increases as certain regions struggle to decarbonize their energy systems. The biggest driver for international trade, with agreement across all models, is the existence of climate change mitigation policy. The stringency of the policy primarily affects the timing of trade ramp-up, but not trade volume. 


\section{0}
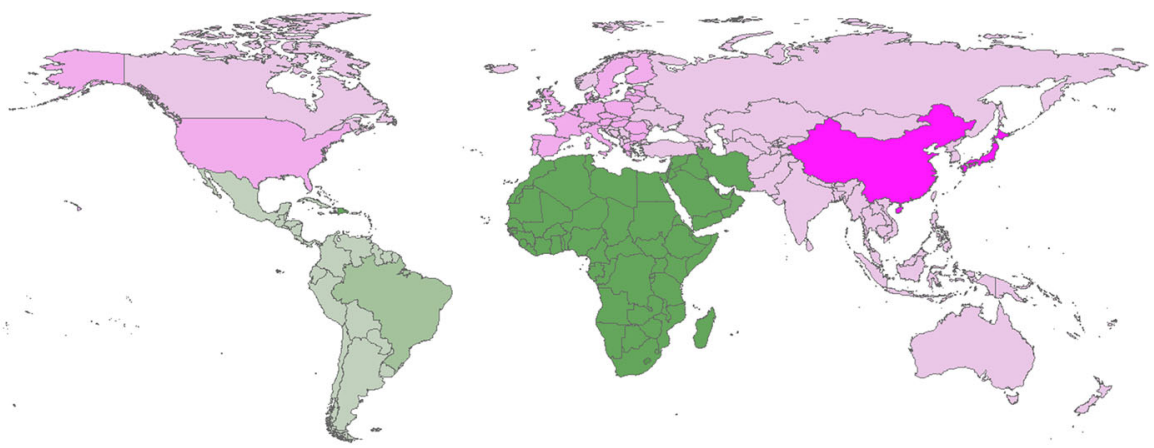

\section{0}
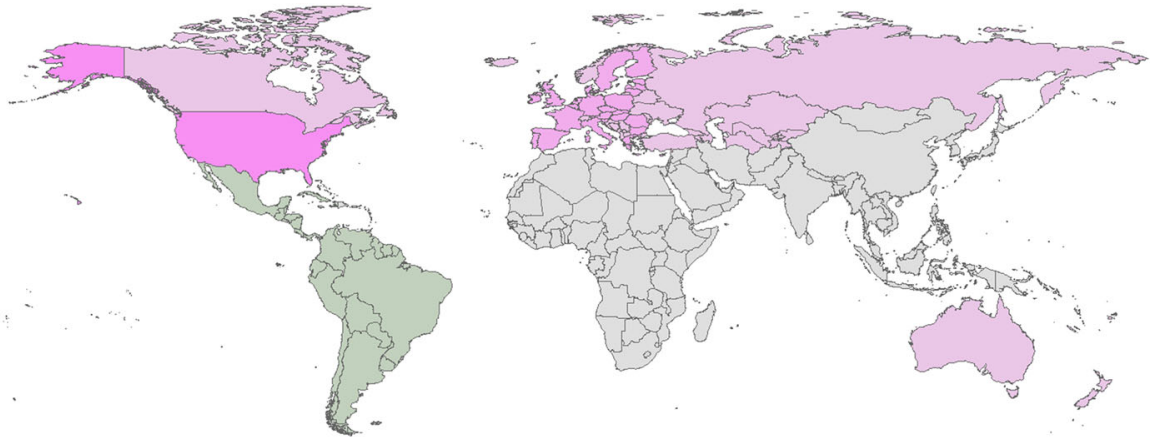

\section{Portion of Global Trade (\%)}

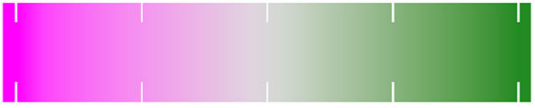

\section{$\begin{array}{lllll}-50 & -25 & 0 & 25 & 50\end{array}$}

Fig. 2 Regional importance in projected international bioenergy trade for 2050 and 2100 for the Budget 1000 scenario. Pink regions are net importers and green regions are net exporters with at least $5 / 8$ models agreeing on the direction of trade. Gray regions indicate less than 5/8 models agree. The intensity of pink/green indicates net imports/exports each region is responsible for with respect to global bioenergy trade, median across agreeing models

\subsection{Energy security}

Regional energy security is portrayed by highlighting (i) the importance of bioenergy as a fraction of TPES, and, (ii) the fraction of bioenergy that is imported. This is shown at the global level in Fig. 3, with a regional disaggregation shown in Fig. S.5 of the Supplementary 
Material. Also shown is the equivalent for fossil fuels (coal, oil, and gas) in 2010. In each panel, the bottom left corner indicates a situation where bioenergy does not play a significant role in TPES, and it is primarily produced domestically, thus highlighting a situation of high (bio)energy security. The top right corner indicates heavy dependence on bioenergy, which is primarily imported (i.e., a state of high (bio)energy insecurity). The top left and bottom right corners show a situation where the region either depends heavily on bioenergy for its TPES, or on imported bioenergy, but not on both. These situations do not represent a significant risk from potential constraints in international trade.

As shown in Fig. 3, despite the increased use and trade of bioenergy, models agree that it does not pose a particular threat to energy security (globally), especially when compared to fossil fuels today. This is primarily because bioenergy is not expected to account for more than $50 \%$ of TPES, even in stringent climate mitigation scenarios. Regionally, the picture is more nuanced. As bioenergy trade increases in climate change mitigation scenarios, most models agree that the USA, EU, the rest of OECD, East and the rest of Asia, and the Former USSR

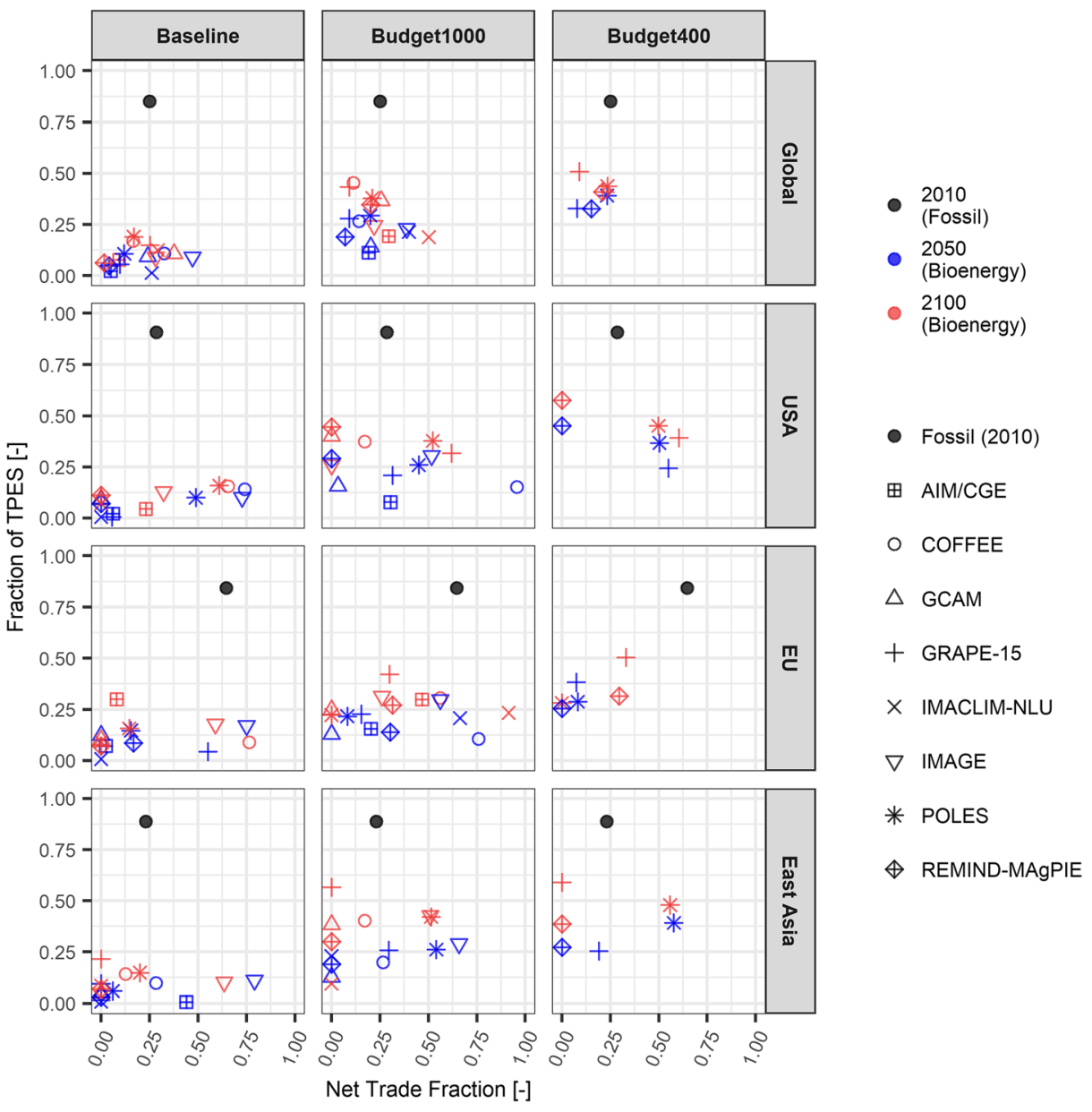

Fig. 3 Share of bioenergy in TPES vs. fraction of produced bioenergy traded in the Baseline and Budget scenarios for selected regions. Also shown are equivalent 2010 values for fossil fuels. A version of the figure including all regions is available in the Supplementary Material 
could experience decreased (bio)energy security, with respect to their Baseline but not significant energy insecurity. In order to further highlight changes in (bio)energy security across regions, we present a compound indicator for bioenergy security (CI) (see the Supplementary Material for details). The CI is the sum of the fraction of bioenergy in regional TPES and the portion of that which is imported (i.e., the axes of Fig. 3). This indicator has a maximum value of 2 (complete insecurity, i.e., bioenergy is 100\% of TPES and is $100 \%$ imported) and a minimum of 0 (no bioenergy insecurity as bioenergy is not used and thus imports are irrelevant). For most models, throughout the century, and with increasing climate policy stringency, the $\mathrm{CI}$ increases, though this may be due to movement along only one of the axes of Fig. 3, thus not necessarily implying increased insecurity. Regions that tend to have a higher CI are the USA, the EU, the rest of OECD, East Asia, and the Former USSR, however, there is a large discrepancy across models. Nonetheless, even in the strictest climate policy scenario, across all regions bioenergy insecurity tends to be less than that of fossil fuels today. In 2010, the CI is estimated to be 0.7-1.4 across regions. Averaged across models and regions, the CI of bioenergy in 2050 is projected to be $0.35,0.46$, and 0.55 for the Budget 1600 , Budget1000, and Budget400 scenarios respectively. By 2100, these increase to 0.56, 0.58, and 0.68 respectively.

In order to highlight potential supply bottlenecks, we compute the Shannon-Weiner index, as used in a number of previous studies (Jansen et al. 2004; Stirling 1994; Jewell et al. 2014), to assess regional diversity of bioenergy supply (see the Supplementary Material for details). The Shannon-Weiner index quantifies the uncertainty in predicting the identity of a random observation within the sample, where the more diverse the sample, the greater the uncertainty of the identity of the observation. The index is a positive real number, with its magnitude denoting the diversity. Figure 4 plots this diversity index versus global bioenergy trade (top row), where the top left corner of each panel indicates a situation of high supply bottleneck. The bottom row shows the difference between the Budget scenarios and the Baseline, showing how climate policy affects these indicators. As shown, in the Baseline, the diversity of supply varies a lot across models, not showing any clear patterns across scenarios or over the projection period. As described above, climate policy leads to increases in global bioenergy trade, however, the effect on supply diversity is mixed. Models displaying a lower supply diversity in the Baseline (AIM/CGE, COFFEE, GRAPE-15 POLES) slightly increase their diversity in the mitigation scenarios as more regions become producers. On the other hand, models showing higher diversity in the Baseline (GCAM, IMACLIM-NLU, REMIND-MAgPIE) show increased concentration as key regions ramp up their exports. The REMINDMAgPIE and AIM models display potential bottlenecks arising from single regions monopolizing supply, the "Latin America" and "M. East and Africa" regions respectively (Note: REMIND-MAgPIE includes Brazil in its Latin America region). Overall, while relatively modest, the increase in bioenergy insecurity with increasing C-budget stringency is mostly due to the increase in trade, rather than the decrease in sources.

\section{Discussion}

\subsection{Bioenergy in mitigation scenarios and the influence of modeling methods}

The results presented in the analysis reflect the diversity of model methods, assumptions, and bioenergy technology portfolios. This leads to a range of projected bioenergy strategies in 

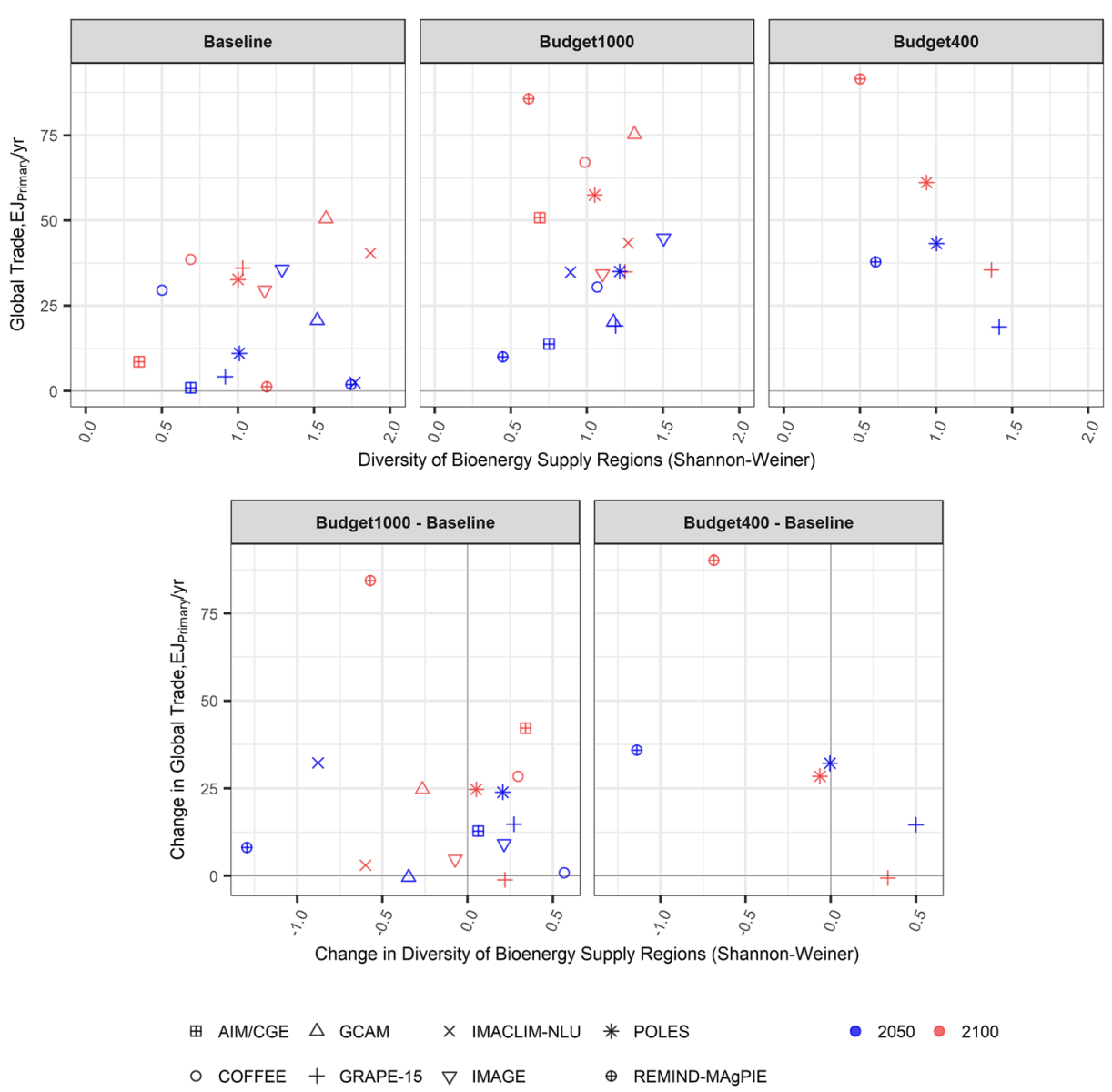

Fig. 4 Gross global trade of bioenergy vs. diversity of supply vs. for the Baseline, Budget1000, and Budget 400 scenarios (top row) and the respective changes between Budget scenarios with respect to the Baseline (bottom row)

climate change mitigation scenarios, which is also reflected in the range of results concerning bioenergy trade. Analysis of the EMF-33 results has highlighted that though specific strategies differ, overall bioenergy plays an important role in climate change mitigation across different targets and bioenergy technology availability constraints (Bauer et al. 2018). Particularly important in the mitigation projections is the use of BECCS, the availability of which is shown to significantly reduce overall mitigation costs (Muratori et al. 2020). Furthermore, it has been shown that while bioenergy technology availability and characterization vary substantially across models, the variation in bioenergy deployment strategies cannot be explained by bioenergy technology portfolios and techno-economic assumptions alone. The representation of systemic issues is also important, including how primary bioenergy supply is modeled and the resultant feedstock costs, the availability and costs of alternative mitigation options in different end uses, the availability and economics of carbon dioxide removal technologies, the speed at which large scale changes in the structure of energy conversion facilities and integration can take place, and the relative demand for different energy services (Daioglou et al. 2020; Rose et al. this issue). 


\subsection{Feasibility and realization of large-scale bioenergy trade}

Our results indicate that international bioenergy trade is projected to reach unprecedented levels, especially in scenarios aiming to significantly mitigate climate change. The stated volumes most likely under report the importance of trade as all results are presented on a nineregion aggregate basis while additional trade will take place within these regions. Although direct bioenergy trade levels have more than tripled over the last decade, it is still at a scale much lower than what is projected here. Achieving the levels projected in this analysis will require a harmonic interplay of several factors across the next decades.

Past developments in direct trade have shown exponential growth patterns for some bioenergy commodities over specific periods and trade routes, particularly in the USA, EU, and Brazil (Proskurina et al. 2017a). The main underlying drivers were market and policy factors creating economically attractive conditions for trade to expand or emerge. Although world regions differ significantly in production costs due to, among others, raw materials, labor, or processing costs, past trade growth patterns have shown to be very policy dependent, with some trade contracts (e.g., in the wood pellet industry) even being directly linked to the payment level and time period of specific policies (Thrän et al. 2017). On the demand side, policies incentivizing or mandating the expansion of renewable energy use in transport and/or heat and power production created the market mechanisms for bioenergy trade to grow. Over the last decade, demand from the European Union dominated world bioenergy trade, but demand in Asia, primarily South Korea and Japan, is rapidly increasing (Chum et al. 2011; Thrän et al. 2017).

Clearly, there is a tremendous gap between the current observed bioenergy trade (approx. 1 $\mathrm{EJ} /$ year) and the volumes presented in this analysis. In order for the projected role, bioenergy can (or may have to) play in mitigating emissions to materialize, the expansion of the bioenergy sector, including trade, cannot be a mere continuation of past developments. To facilitate bioenergy trade in the order of magnitude discussed in the above results, there needs to be a trend towards higher energy density products and/or intermediates, which increases bulk density and trade flow efficiency (i.e., more Joules being transported per ship/rail car/ etc.). Furthermore, future bioenergy trade streams need to become physically integrated into fossil fuel trade infrastructure, particularly concerning rail, road, and harbor infrastructure. This would avoid potential logistical and physical constraints (especially in the short term) and would be more cost effective than building additional capacity. Large-scale trade of bioenergy and its integration in existing capital and infrastructure would benefit from bioenergy carriers being commodities, i.e., homogenous, storable, and flowable products (see Olsson et al. (2016) for a detailed discussion regarding biomass markets). Commoditization of these intermediates would also create fungibility across various purposes and markets. The IAMs used in this study treat bioenergy as such a commodity, however, they do not include explicit representation of bioenergy infrastructure. Thus, how the costs, constraints, or availability of infrastructure may affect the projections of bioenergy deployment or its trade are not considered.

Challenges to expand large-scale primary bioenergy production on the grower level and the processing of feedstock into high energy density intermediates/products are manifold. Largescale production of bioenergy hinges on grower participation (e.g., in new practices such as energy crop production), which is linked to price developments in cash crop markets, among others. Expansion of processing infrastructure is heavily dependent on the access to and the conditions of financing. Those in turn are influenced by the level of technology readiness and investment attractiveness, which depend on the maturity of the respective market including long-term/expected prices. Finally, institutional barriers remain, including a lack of 
homogenous trade regulations and sustainability frameworks. Sustainability certification, standards, and related carbon accounting across world regions are required to minimize leakage effects and ensure the GHG emission reduction potential of bioenergy, especially under increasing trade (Otto et al. 2015; Popp et al. 2014). Unless these are addressed, large scale trade of bioenergy could undermine the efficacy of mitigation policies. This is important in the context of projections presented here, where a uniform global greenhouse gas price is applied. Accordingly, the results presented here highlight a situation where bioenergy demand (or competitiveness) increases simultaneously across regions, and land-use emissions are priced. Thus, in parallel to bioenergy production, there are also broader changes in land use including the protection of carbon-rich biomes, afforestation, and intensification of agricultural production (Rose et al. this issue).

\subsection{Geopolitical and social implications}

The importance of bioenergy to meet strict climate targets may raise concerns about the possibility of single countries or regions exerting disproportionate control over this market. The results presented here do not give credence to these concerns. This is primarily because a high diversity in supply regions could help manage risk concerning bioenergy security of net importing regions. Another dimension of security involves the negative effects of commodity booms (and busts). These include "Dutch Disease" (increased revenues from production and export of a commodity leading to a real appreciation of the local currency, negatively affecting other local industries), land grabbing and competition with food production, environmental degradation, effects on biodiversity, and increased political instability (Cavalcanti et al. 2015; Flexor and Pereira-Leite 2017; Frankel 2010; Corden and Neary 1982). This is particularly pertinent for Brazil where previous dependence on commodity exports (particularly agricultural products) made the region's economy sensitive to global commodity prices. Given the sustained increase of bioenergy demand in future projections, and the subsequent increase of bioenergy prices, the models project very high financial flows towards exporting countries such as Brazil (section 4.1). Given that many models project that Brazilian bioenergy production is primarily for export, the country may be particularly sensitive to market fluctuations. These concerns may also become important for other Latin American countries and Sub-Saharan Africa as well as for regions dependents on large imports.

As noted in section 3, IAMs do not typically include restrictions to trade through tariff and non-tariff barriers. The presence of such barriers would affect the results by changing the competitiveness of bioenergy vis-à-vis other renewable energy options and the most attractive trade routes. Historically, tariffs regulated total trade volumes, but other restrictions, e.g., biofuel feedstock limitations, had a more prominent role in defining trade routes (Junginger et al. 2011; Lamers et al. 2011). This includes the 2018 EU Renewable Energy Directive which sets constraints on the volume of food-based biofuels, which can be consumed in the EU (EU 2018). This will limit the import of 1st generation biofuels into the EU, but likely lead to an increase in the import (or local production) of lignocellulosic biofuels. This is in agreement with the projections presented here since almost all of the bioenergy used in these pathways comes from lignocellulosic feedstocks (including residues and forestry) (Daioglou et al. 2020; Rose et al. this issue).

This study has focused on the inter-regional trade of bioenergy only. Demand, production, and international trade of broader agricultural commodities including food, feed, and forestry, are also implicitly included in the model projections. Despite the large increase in bioenergy 
consumption in the scenarios, globally (and for most regions), this does not lead to decreases in agricultural production. In fact, most models show that regional agricultural production increases throughout the projection period, in tandem with increased bioenergy production (see Fig. S.6 of the Supplementary Material). This is achieved through the use of residues as primary bioenergy (up to $50 \%$ of bioenergy supply) and projected increases in crop yields and livestock production intensity (for further details see Rose et al. (this issue) and Hansen et al. (2019)). Yet, the EMF-33 scenarios do show that large scale use of bioenergy may increase (regional) food prices and threaten food security. The risk does not negate the use of bioenergy but shows the importance of careful bioenergy implementation (Hasegawa et al. 2020).

\section{Conclusions}

In this paper, we present projections of international bioenergy trade among nine world regions, showing results for several integrated assessment models and scenarios with varying assumptions on bioenergy technology availability and climate change mitigation targets.

Global international trade of bioenergy is projected to increase significantly The projections highlight that by the middle of the twenty-first century, the trade of bioenergy among the nine regions represented in this study is likely to increase significantly from today's levels but will not surpass the current levels of fossil fuels. This trade is necessary in order to meet the demand of bioenergy which is projected to arise in climate change mitigation strategies of all regions, with up to $50 \%$ of bioenergy demand projected to be traded among these regions from 2050 onwards (25\% median across models). This observation is robust to assumptions on bioenergy technology availability, with bioenergy demand (and trade) increasing irrespective of the availability of BECCS or advanced biofuel technologies. Furthermore, by comparing the different Budget scenarios it is seen that $1.5^{\circ} \mathrm{C}$ mean global temperature rise pathways do not imply significantly greater trade volumes by 2100 than a $2{ }^{\circ} \mathrm{C}$ pathway, but rather faster growth rates in international trade in the first half of the twenty-first century.

Most models suggest that Latin America and Africa could be the main net exporting regions, with EU, the USA, and Asia likely being net importers The large volumes of bioenergy traded may have significant implications concerning potential revenue sources, economic development, and trade imbalances. The important role of Brazil in supplying bioenergy to the rest of the world, and what this means concerning Brazilian land use and energy crop yields is further discussed in Köberle et al. (this issue). Given that increased bioenergy trade may lead to significant land-use changes in supplying countries, attention must be paid on negative consequences for emissions, biodiversity, water use, and the macroeconomic implications of dependence on global commodity markets.

\section{Though many regions are likely to depend on imported bioenergy, this does not likely} lead to significant additional energy security concerns This is because climate change mitigation pathways are likely to lead to an increase in energy diversity, with bioenergy making up less than $50 \%$ of TPES of different regions. Thus, future energy systems do not depend on a single primary energy source as much as they depend on (often imported) fossil fuels today. Furthermore, model projections indicate that there are multiple bioenergy supply regions offering supply diversity. 


\section{Given the importance of international bioenergy trade to meet strict climate change} mitigation goals, successful mitigation strategies depend on the development of global bioenergy markets and relevant legislation This requires investment in processing infrastructure which would increase the energy density of bioenergy carriers and make bioenergy into a homogenous, storable, and fungible commodity. This can be partly overcome by integrating bioenergy trade streams into existing fossil fuel trade infrastructure. Besides technological aspects, there is a need to improve access and conditions of financing for different actors (farmers, primary bioenergy processing/converting facilities). The availability of low-interest rate loans and/or public procurement can stimulate both the demand of bioenergy and the participation of farmers in international markets (Lamers et al. 2012). The latter applies mainly to developing countries that might be keen to set up projects with the aim to export. Finally, it is important to create homogenous trade regulations and explore the possibility of sustainability frameworks on the protection of land-based carbon stocks. This is essential to safeguarding GHG savings and manage leakage effects.

Acknowledgements The authors would like to thank the IEA Bioenergy Task 40 for their helpful comments throughout the writing of this paper. Particular thanks are extended to Daniela Thrän, Fabian Schipfer, Olle Olsson, and Lena Bruce. SF is supported by the Environment Research and Technology Development Fund (21702) of the Environmental Restoration and Conservation Agency. The views and opinions expressed in this paper are those of the authors alone and do not reflect the positions of their institutions or governments.

Open Access This article is licensed under a Creative Commons Attribution 4.0 International License, which permits use, sharing, adaptation, distribution and reproduction in any medium or format, as long as you give appropriate credit to the original author(s) and the source, provide a link to the Creative Commons licence, and indicate if changes were made. The images or other third party material in this article are included in the article's Creative Commons licence, unless indicated otherwise in a credit line to the material. If material is not included in the article's Creative Commons licence and your intended use is not permitted by statutory regulation or exceeds the permitted use, you will need to obtain permission directly from the copyright holder. To view a copy of this licence, visit http://creativecommons.org/licenses/by/4.0/.

\section{References}

Bauer N, Rose S, Van Vuuren D, Weyant J, Wise M, Cui Y, Daioglou V, Fujimori S, Gidden M, Kato E, Kitous A, Mima S, Leblanc F, Sands R, Sano F, Strefler J, Tsutsui J (2018) Global energy sector emission reductions and bio-energy use: overview of the EMF-33 model comparison. Clim Chang 16

Cavalcanti T, Mohaddes K, Raissi M (2015) Commodity price volatility and the sources of growth. J Appl Econ 30:857-873

Cherp A, Jewell J (2011) The three perspectives on energy security: intellectual history, disciplinary roots and the potential for integration. Curr Opin Environ Sustain 3:202-212

Cherp A, Jewel J, Vinichenko V, de Cian E (2016) Global energy security under different climate policies, GDP growth rates and fossil resource availabilities. Clim Chang 136:83-94

Chum H, Faaij A, Moreira J, Berndes G, Dhamija P, Dong H, Gabrielle B, Goss Eng A, Lucht W, Mapako M, Masera O, Mcintyre T, Minowa T, Pingoud K (2011) Bioenergy. In: Edenhofer O, Pichs-Madruga R, Sokona Y, Seyboth K, Matschoss P, Kadner S, Zwickel T, Eikemeier P, Hansen G, Schlömer S, von Stechow C (eds) IPCC special report on renewable energy sources and climate change mitigation. Cambridge University Press, Cambridge, UK and New York, NY, USA

Clarke L, Jiang K, Akimoto K, Babiker M, GB, Fisher-Vanden K, Hourcade JC, Krey V, Kriegler E, Löschel A, Mccollum D, Paltsev S, Rose S, Shukla PR, Tavoni M, van der Zwaan B, van Vuuren DP (2014) Assessing transformation pathways. In: Edenhofer O, Pichs-Madruga R, Sokona Y, Farahani E, Kadner S, Seyboth K, Adler A, Baum I, Brunner S, Eikemeier P, Kriemann B, Savolainen J, Schlömer S, von Stechow C, Zwickel T, Minx JC (eds) Climate change 2014: mitigation of climate change. Contribution of Working Group III to 
the Fifth assessment Report of the Intergovernmental Panel on Climate Change. Cambridge University Press, Cambridge, United Kingdom and New York, NY, USA

Corden M, Neary JP (1982) Booming sector and de-industrialisation in a small open economy. Econ J 92:825848

Creutzig F, Ravindranath NH, Berndes G, Bolwig S, Bright R, Cherubini F, Chum H, Corbera E, Delucchi M, Faaij A, Fargione J, Haberl H, Heath G, Lucon O, Plevin R, Popp A, Robledo-Abad C, Rose S, Smith P, Stromman A, Suh S, Masera O (2015) Bioenergy and climate change mitigation: an assessment. GCB Bioenergy 7:916-944

Dadhich P (2017) Trans boundary flows of solid biomass waste streams in Europe and its effect on the country's energy system. M.Sc, Aalto University

Daioglou V, Rose S, Bauer N, Kitous A, Muratori M, Sano F, Fujimori S, Gidden M J, Kato E, Keramidas K, Klein D, Leblanc F, Tsutsui J, Wise M and van Vuuren D (2020) Bioenergy technologies in long-run climate change mitigation: results from the EMF-33 study. Clim Chang 20

EU (2018) Directive 2018/2001 of the European Parliament and of the council of 11 December 2018 on the promotion of the use of energy from renewable sources (recast). Off J Eur Union 128

Flexor G, Pereira-Leite S (2017) Land market and land grabbing in Brazil during the commodity boom of the 2000s. Contexto Int 38:28

Frankel JA (2010) The natural resource curse: a survey. Working Paper 15836. Cambridge: National Bureau of Economic Research

Gale F, Hansen J \& Jewison M (2015) China's growing demand for agricultural imports. U.S. Department of Agriculture

Hansen S, Daioglou V, Steinmann Z, Stefan F, Popp A, Brunelle T, Pekka L, Hasegawa T, Huijbrechts M, van Vuuren D (2019) Biomass residues as 21st century bioenergy feedstock - a comparison of eight integrated assessment models. Clim Chang: 18

Hansson J, Berndes G (2009) Future bioenergy trade in the EU: modelling trading options from a costeffectiveness perspective. J Clean Prod 17:S27-S36

Hasegawa T, Sands R, Brunelle T, Cui Y, Frank S, Fujimori S, Popp A (2020) Food security under high bioenergy demand toward long-term climate goals. Clim Chang 15

Jansen JC, van Arkel WG \& Boots MG (2004) Designing indicators of long-term energy supply security. Energy Research Centre of the Netherlands

Jewell J, Cherp A, Riahi K (2014) Energy security under de-carbonization scenarios: an assessment framework and evaluation under different technology and policy choices. Energy Policy 65:743-760

Jewell J, Vinichenko V, Mccollum D, Bauer N, Riahi K, Aboumahboub T, Fricko O, Harmsen M, Kober T, Krey V, Marangoni G, Tavoni M, van Vuuren DP, van der Zwaan B, Cherp A (2016) Comparison and interactions between the long-term pursuit of energy independence and climate policies. Nat Energy 1:16073

Junginger HM, van Dam J, Zarrilli J, Mohamed S, Marchal FA, Faaij A (2011) Opportunities and barriers for international bioenergy trade. Energy Policy 39:2028-2042

Köberle A, Daioglou V, Rochedo P, Lucena A, Szklo A, Fujimori S, Brunelle T, Kato E, Kitous A, van Vuuren $\mathrm{D} \&$ Schaeffer $\mathrm{R}$ (this issue) The role of bioenergy in mitigation strategies for Brazil: a multi-model comparison exercise In review

Lamers P, Hamelinck C, Junginger M, Faaij A (2011) International bioenergy trade - a review of past developments in the liquid biofuel market. Renew Sust Energ Rev 15:2655-2676

Lamers P, Junginger M, Hamelinck C, Faaij A (2012) Developments in international solid biofuel trade-an analysis of volumes, policies, and market factors. Renew Sust Energ Rev 16:3176-3199

Lamers P, Rosillo-Calle F, Pelkmans L (2014a) Developments in international liquid biofuel trade. In: Junginger HM, Goh CS, Faaij A (eds) International bioenergy trade: history, status \& outlook on securing sustainable bioenergy supply, demand and markets. Springer, Dordrecht

Lamers P, Marchal FA, Heinimö J (2014b) Global Woody biomass trade for energy. In: Junginger HM, Goh CS, Faaij A (eds) International bioenergy trade: history, status \& outlook on securing sustainable bioenergy supply, demand and markets. Springer, Dordrecht

MAPA (2012) Brazilian agricultural foreign trade: main markets and products. Brasilia: Ministry of Agriculture, Livestock and Food Supply

Matzenberger J, Kranzl L, Tromborg E, Junginger M, Daioglou V, Sheng Goh C, Keramidas K (2015) Future perspectives of international bioenergy trade. Renew Sust Energ Rev 43:926-941

Muratori M, Calvin K, Wise M, Kyle P, Edmonds J (2016) Global economic consequences of deploying bioenergy with carbon capture and storage. Environ Res Lett 11:9

Muratori M, Rose S, Bauer N, Wise M, Daioglou V, Kato E, van Vuuren D, Weyant J (2020) Bioenergy and carbon capture and storage (BECCS): results from the EMF-33 study. Clim Chang 17

Olsson O, Lamers P, Schipfer F, Wild M (2016) Commoditization of biomass markets. In: Lamers P, Searcy E, Hess R, Stichnothe H (eds) Developing the global bioeconomy. Academic Press 
Otto SAC, Gernaat DEHJ, Isaac M, Lucas PL, van Sluisveld MAE, van den Berg M, van Vliet J, van Vuuren DP (2015) Impact of fragmented emission reduction regimes on the energy market and on $\mathrm{CO} 2$ emissions related to land use: A case study with China and the European Union as first movers. Technol Forecast Soc Chang 90:220-229

Popp A, Humpenöder F, Weindl I, Bodirsky BL, Bonsch M, Lotze-Campen H, Müller C, Biewald A, Rolinski S, Stevanovic M, Dietrich JP (2014) Land-use protection for climate change mitigation. Nat Clim Chang 4: 1095-1098

Proskurina S, Junginger HM, Heinimö J, Tekinel B \& Vakkilainen E (2017a) Global biomass trade for energy: part 2 - production and trade streams of wood pellets, liquids biofuels, industrial roundwood and emerging energy biomass. Biofuels Bioprod Bioref

Proskurina S, Junginger HM, Heinimö J \& Vakkilainen E (2017b) Global biomass trade for energy: part 1 statistical and methodological considerations. Biofuels Bioprod Bioref

Rogelj J, Luderer G, Pietzcker R, Kriegler E, Schaeffer M, Krey V, Riahi K (2015) Energy system transformations for limiting end-of-century warming to below $1.5^{\circ} \mathrm{C}$. Nat Clim Chang 5:519-527

Rose S, Kriegler E, Bibas R, Calvin K, Popp A, van Vuuren DP, Weyant JP (2014) Bioenergy in energy transformation and climate management. Clim Chang 123:477-493

Rose S, Popp A, Fujimori S, Havlik P, van Vuuren D, Weyant J, Wise M (this issue) Global biomass supply modeling for long-run management of the climate system. Clim Chang

Searle S, Malins C (2015) A reassessment of global bioenergy potential in 2050. GCB Bioenergy 7:328-336

Stirling A (1994) Diversity and ignorance in electricity supply investment: addressing the solution rather than the problem. Energy Policy 22:195-216

Stopford M (2009) Maritime economics. Routledge, London and New York

Thrän D, Peetz D, Schaubach K (2017) Global wood pellet industry and trade study 2017. IEA Bioenergy Task 40

Publisher's note Springer Nature remains neutral with regard to jurisdictional claims in published maps and institutional affiliations. 


\section{Affiliations}

Vassilis Daioglou ${ }^{1,2} \cdot$ Matteo Muratori $^{3} \cdot$ Patrick Lamers $^{3} \cdot$ Shinichiro Fujimori ${ }^{4,5}$ - Alban Kitous $^{6}$ - Alexandre C. Köberle ${ }^{7}$ - Nico Bauer ${ }^{8} \cdot$ Martin Junginger $^{2}$ • Etsushi Kato ${ }^{9}$. Florian Leblanc $^{10} \cdot$ Silvana Mima $^{11} \cdot$ Marshal Wise $^{12} \cdot$ Detlef P. van Vuuren $^{1,2}$

\section{Vassilis Daioglou}

Vassilis.daioglou@pbl.nl

1 PBL Netherlands Environmental Assessment Agency, PO Box 30314, 2500 GH The Hague, The Netherlands

2 Copernicus Institute of Sustainable Development, Utrecht University, Princetonlaan 8a, 3584 CB Utrecht, The Netherlands

3 National Renewable Energy Laboratory, Golden, CO, USA

4 Department of Environmental Engineering, Kyoto University, Kyoto, Japan

5 National Institute for Environmental Studies, Center for Social and Environmental Systems Research, Tsukuba, Ibaraki 305-8506, Japan

6 Joint Research Centre of the European Commission, Seville, Spain

7 Energy Planning Program, Graduate School of Engineering, Universidade Federal do Rio de Janeiro, Rio de Janeiro, Brazil

8 Potsdam Institute for Climate Impact Research (PIK), Potsdam, Germany

9 The Institute of Applied Energy, Minato, Tokyo 105-0003, Japan

10 International Research Center on the Environment and Development (CIRED), Nogent-sur-Marne, France

11 GAEL, CNRS, Grenoble INP, INRA, Univ. Grenoble Alpes, 38400 Saint Martin d'Hères, France

12 Joint Global Change Research Institute, Pacific Northwest National Laboratory and the University of Maryland, College Park, USA 